\title{
Managing opioid-induced constipation in advanced illness: focus on methylnaltrexone bromide
}

\author{
This article was published in the following Dove Press journal: \\ Therapeutics and Clinical Risk Management \\ 9 February 2010 \\ Number of times this article has been viewed
}

\author{
Katri Elina Clemens ${ }^{1,2}$ \\ Eberhard Klaschik' \\ 'Department of Science and Research, \\ Centre for Palliative Medicine, \\ University of Bonn, Germany; \\ ${ }^{2}$ Department of Palliative Medicine \\ and Pain Therapy, Malteser Hospital \\ Bonn/Rhein-Sieg, Germany
}

\begin{abstract}
Constipation is a common symptom in palliative care patients which can generate considerable suffering. There is uncertainty about the choice of treatment options from varying recommendations for management of constipation and a varying clinical practice in palliative care settings. The purpose of the review was to evaluate the current recommendations of therapy guidelines for the management of opioid-induced constipation in palliative care patients with a focus on methylnaltrexone bromide. Recent findings in the literature and related information on the opioid-induced gastrointestinal disorders in patients with advanced illness, as well as information on the opioid-antagonist methylnaltrexone, are discussed. Knowledge of the role of definitions, the causes of constipation and the pathophysiology of opioid-induced constipation must be given high priority in the treatment of patients receiving opioids. Diagnosis and therapy of constipation, therefore, should relate to findings in clinical investigation. Opioid-induced constipation and its adequate treatment is an important issue for patients with advanced illness and also poses therapeutic challenge for clinicians in daily routine. Methylnaltrexone bromide may represent an important therapeutic option for palliative care patients who are suffering from opioid-induced constipation with failure of conventional prophylactic oral laxative treatment.
\end{abstract} Keywords: opioid-induced constipation, palliative care, opioids, methylnaltrexone bromide

\section{Introduction}

Constipation is a distressing complication for oncology patients that is often underassessed and undertreated and may occur as a side effect of tumor growth or an adverse effect of drug therapy. However, constipation is one of the most frequent and persistent side effects of opioid therapy, and it is feared by many patients as much as the symptom of pain. Prophylaxis and symptomatic treatment of opioid-induced constipation are essential and the most effective approach to its management. Unlike other side effects of opioid medication, such as nausea and emesis, there is no, or extremely slow, tolerance build-up to the constipatory effects of opioids. In patients with incurable progressive and far-advanced disease, for whom prognosis is limited and the focus of care is on the quality of life, opioid-induced constipation remains a significant clinical problem. Particularly in patients with advanced-stage tumor disease treatment must be undertaken with careful consideration of their physical activity and dietary needs.

The prevalence of constipation in patients with cancer ranges from $70 \%$ to $100 \% \cdot{ }^{1-3}$ In general terms, all patients treated with opioids will require some degree of clinical intervention to relieve the discomfort imposed by constipation. The evidence suggests that up to $90 \%$ of patients treated with opioids will experience chronic constipation

submit your manuscript | www.dovepress.con 
and of those receiving standard laxative treatments over half will remain dissatisfied with the outcome. ${ }^{1}$ Furthermore, the treatment of constipation, in general, carries an economic burden for the health system, in terms of the costs associated with hospital admissions and length of stay.

Although few evidence-based data exist on the specific use of laxatives in palliative medicine, ${ }^{4,5}$ long years of clinical experience have yielded therapeutic recommendations. ${ }^{4,6,7}$

\section{Constipation}

The term constipation describes the subjective impression that the contents of the intestine are not evacuated at adequate frequency, in adequate volumes, the consistency of the stool is too hard, or/and the stool is passed with discomfort. ${ }^{8,9}$

Untreated constipation can contribute to secondary complications such as abdominal distension, urinary retention, nausea, vomiting, and anorexia, as well as the development of hemorrhoids, anal fissures, perianal abscesses, and intestinal obstruction. ${ }^{1,7,10-13}$ Constipation may be annoying and uncomfortable and can lead to life-threatening fecal impaction. Patients with fecal impaction may present with circulatory, cardiac, or respiratory symptoms instead of gastrointestinal symptoms. ${ }^{1,7,10-13}$

In advanced-stage tumor disease, constipation is a frequent symptom. In the palliative care setting it occurs particularly in immobile patients, whose diet is not rich enough in fiber and who drink too little fluid. In addition, they often take drugs that induce constipation, such as opioids. Since these patients can increase neither their physical activity nor their fluid and food/fiber intake, treatment with laxatives is indicated at an early stage and always at the start of opioid therapy. It is known that constipation occurs more often in women and that the incidence of constipation increases with age. ${ }^{14-16}$

Differentiating between the normal range of evacuation of stools and a diagnosis of constipation is not always easy. Table 1 provides indicators for differentiation. ${ }^{16-18}$ Constipation can be drug-induced or have organic or functional causes (Table 2). ${ }^{16-18}$

\section{Pathophysiology of opioid-induced constipation}

Opioid-induced constipation is predominantly mediated by gastrointestinal $\mu$-opioid receptors. ${ }^{19,20}$

Peripheral as well as intrathecal and intraventricular administration of opioids will lead to a prolonged colon passage of the bowel content, since opioid-induced constipation is caused by linkage of the opioid receptors in the gut and the central nervous system. ${ }^{21,22}$ The inhibition of the release of acetylcholine from the myenteric plexus leads to a relaxation of the longitudinal musculature of the colon and small intestine. Subsequently, the propulsive motor activity decreases. Furthermore, opioids cause an increase in segmental intestinal contraction. This will cause a prolonged transit of intestinal contents, leading to a withdrawal of water and fecal impaction. Further, the intestinal, gastric, biliary, and pancreatic secretions decrease. An increase in the tonus of the intestinal sphincters and a decrease in the defecatory reflex add to the constipatory effect. Meissner et al in an unrandomized controlled study, showed that enteral application of naloxone can reduce opioid-induced constipation without impairing or suspending the pain-relieving effects of the opioid. ${ }^{23}$ A combination drug consisting of the opioid oxycodone and the opioid antagonist naloxone has been available for some time. Shaiova et al reviewed the role of methylnaltrexone, a peripheral opioid receptor antagonist, in the management of opioid-induced constipation. ${ }^{24}$

\section{Treating opioid-induced constipation in palliative care patients}

In palliative medicine, the functional causes of constipation far exceed the organic ones, and opioid-induced constipation is of particular importance. If drugs are the cause of constipation then consideration needs to be given to stopping these drugs. This is, however, not sensible in the context of analgesia with opioids.

The pharmacological management of opioid-induced constipation generally involves two approaches: nonspecific

Table I Differentiation between normal stool evacuation and constipation

\begin{tabular}{lll}
\hline Variable & Normal & Constipation likely \\
\hline Frequency of stools & $\geq 3$ evacuations per week & $\leq 3$ evacuations per week \\
Weight of stools & and $\leq 3$ evacuations per day & $<35 \mathrm{~g} /$ day \\
Weight of water in stools & $35-150 \mathrm{~g} /$ day & $<70 \%$ \\
Time taken by gastrointestinal passage & ca $70 \%$ & $>5$ days \\
\hline
\end{tabular}


Table 2 Possible causes of constipation

\begin{tabular}{lll}
\hline Organic & Functional & Drug-induced \\
\hline Diverticulitis & Prolonged colon & Opioids \\
Tumors & passage & Antibiotics \\
Inflammation in the & Impaired defecation & Anticholinergics \\
anal area & Insufficient intake of & Antihypertensive drugs \\
Neurological & fluids & Anticonvulsive drugs \\
disorders & Low fiber diet & Antidepressants \\
Endocrine & Immobility & Drugs for Parkinson's \\
disorders & & disease \\
Metabolic causes & & Diuretics \\
& & Neuroleptics \\
Recto-anal disorders & & Antacids \\
Megacolon & & \\
\hline
\end{tabular}

treatment with laxatives and prokinetic drugs, and specific treatment with opioid receptor antagonists. ${ }^{10,23,25}$

Prophylactic treatment with laxatives should be initiated and sustained, for as long as the opioid is given. The choice of substance(s) for symptomatic drug treatment with laxatives has to be made accordingly. Often synergism of multiple categories of agents is required for successful laxation.

Laxatives (Latin: laxare - to loosen) are substances that accelerate defecation. Most laxatives improve the consistency of the stools by luminal water retention or by increasing the secretion of water into the lumen of the intestine and/or stimulating peristalsis. ${ }^{16}$

If the nonspecific regimens do not provide satisfactory relief from the gastrointestinal manifestations of opioidinduced constipation, specific treatment options with peripherally restricted opioid receptor antagonists such as methylnaltrexone bromide may be more efficacious for treatment of opioid-induced constipation and may thereby improve bowel function.

\section{Methylnaltrexone bromide}

One of the substances investigated for the treatment of opioid-induced constipation is methylnaltrexone, a quaternary derivate of the pure opioid-antagonist naltrexone, which results in a distinct pharmacological profile. ${ }^{11,26}$ Methylnaltrexone was developed at the University of Chicago, USA, and out-licensed to UR Labs in 1985. N-methylation of the uncharged systemic opioid antagonist, naltrexone, ${ }^{27}$ results in a charged derivative, methylnaltrexone, which has proven ability to cross the blood-brain barrier in humans because of its polarity and low lipid solubility. ${ }^{11,28}$
A number of phase I and II studies have established the pharmacodynamic, pharmacokinetic, therapeutic and safety profile of methylnaltrexone. ${ }^{29-32}$

The drug has been formulated as a solution for intravenous or subcutaneous administration and as capsules/tablets for oral administration. Both the parenteral and oral formulations, as well as single and repeated dosage regimens have been found efficacious in preventing the opioid-induced prolongation of gastric emptying and orocecal transit time without significantly attenuating the analgesic effect of opioids. ${ }^{30,31,33}$ In this context it is no less interesting that methylnaltrexone may ameliorate opioid-induced urinary retention. ${ }^{33,34}$

Selective blockade of peripheral gastrointestinal $\mu$-opioid receptors might relieve constipation without compromising centrally mediated effects of opioid analgesia or precipitating withdrawal.

In healthy volunteers, methylnaltrexone reversed the morphine-induced delay in both gastric emptying and oral-cecal transit time without affecting analgesia. ${ }^{33,35-39}$ The efficacy and safety of methylnaltrexone bromide was demonstrated in two randomized, double-blind and placebocontrolled studies, as well as in one single-blinded phase II study that also showed that methylnaltrexone rapidly induced laxation (Table 3). ${ }^{39-41}$ The patient groups in the studies by Yuan et $\mathrm{al}^{40,41}$ received methylnaltrexone for methadoneinduced constipation, and Thomas et $\mathrm{al}^{39}$ demonstrated their findings in patients with advanced illness and opioid-induced constipation.

In both studies, patients had advanced terminal illness and limited life expectancy, the majority having a primary diagnosis of incurable cancer; other primary diagnoses included end-stage chronic obstructive pulmonary disease, cardiovascular disease/heart failure or other advanced illnesses. Prior to screening, patients had opioid-induced constipation defined as either $<3$ bowel movements in the preceding week or no bowel movement for $>2$ days.

Methylnaltrexone bromide-treated patients had a higher rate of laxation within 4 hours of the initial dose (48\%) than placebo-treated patients (16\%) (95\% confidence interval [CI] $7 \%$ to $49 \% ; P<0.0001)$. Methylnaltrexone bromidetreated patients also had significantly higher rates of laxation within 4 hours after at least 2 of the first 4 doses (52\%) than did placebo-treated patients $(9 \%)(P<0.0001)$. Stool consistency was not meaningfully improved in patients who had soft stool at baseline. No episodes of generalized opioid withdrawal or a form of gut hypermotility known as "gut withdrawal syndrome" were observed, and there was no 


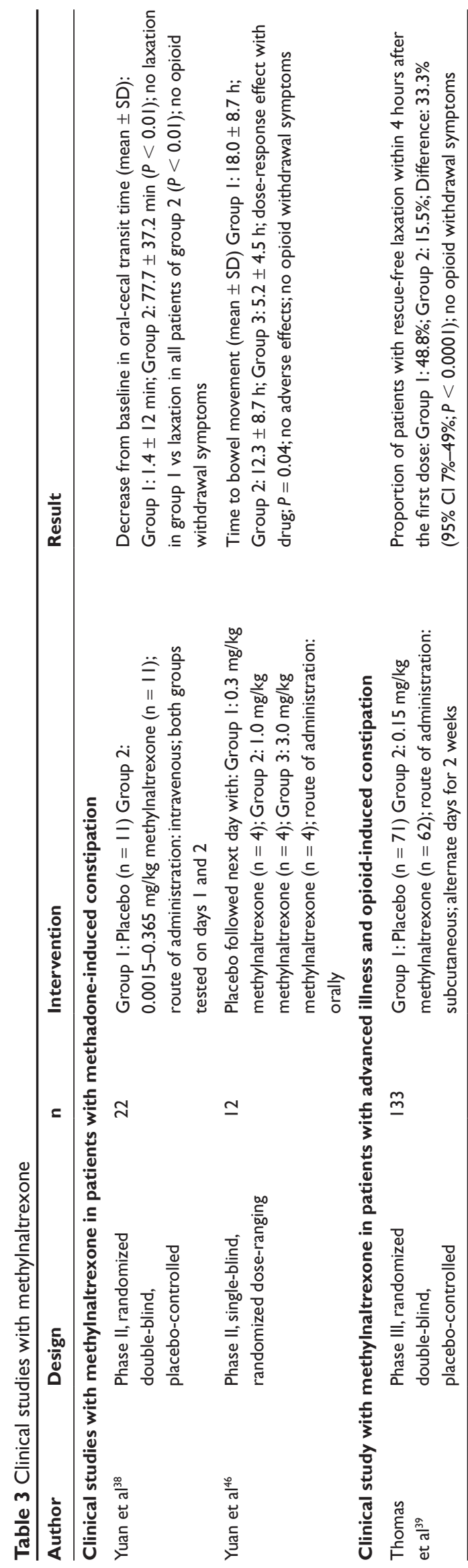

evidence of antagonism of analgesia. Futhermore, in both studies there was no evidence to suggest differential effects of age or gender on safety or efficacy. The effect on race could not be analyzed because the study population was predominally Caucasian (88\%). ${ }^{39,40}$

Although methylnaltrexone was significantly more effective than placebo, it was somewhat disappointing that in both phases of the study the drug produced rescue-free laxation in only about half of the patients. There may be several reasons for this relative high failure rate. For example, although all patients received opioids, the predominant causes of constipation among the patients who did not respond to methylnaltrexone could have been the effects of other drugs or disease processes unrelated to actions mediated by opioid receptors. ${ }^{42}$ Additional explanations could be that methylnaltrexone may behave as a partial agonist. ${ }^{43}$

McNicol et $\mathrm{al}^{44}$ showed in a systematic review of four studies that, on average, gastrointestinal transit time in patients given methylnaltrexone was reduced by 52 minutes (95\% CI -73 to -32 minutes) compared with placebo. ${ }^{36-38,40}$ Methylnaltrexone reduced the mean transit time to 93 to 110 from 140 to 163 minutes for placebo.

At therapeutic intravenous doses of 0.3 to $0.45 \mathrm{mg} / \mathrm{kg}$ and oral doses up to $19 \mathrm{mg} / \mathrm{kg}$ methylnaltrexone is well tolerated and able to relieve constipation in methadone-dependent individuals and patients with advanced illness who need opioids for pain control. ${ }^{30,45}$

The European Medicines Agency approved subcutaneous administration of methylnaltrexone for treatment of opioid-induced constipation in adults with advanced illness. Methylnaltrexone should be used in patients with opioid-induced bowel dysfunction who do not respond to a reasonable laxative regimen, in combination with the laxative regimen. The recommended dose is $8 \mathrm{mg}$ for patients weighing 38 to $61 \mathrm{~kg}$ and $12 \mathrm{mg}$ for patients weighing 62 to $114 \mathrm{~kg}$, every 2 days. Outside these weight ranges, the dose should be $0.15 \mathrm{mg} / \mathrm{kg}^{46,47}$

Defecation can be expected within 4 hours after the first dose in about $50 \%$ of patients. ${ }^{39}$

\section{Pharmacokinetics of methylnaltrexone bromide}

Methylnaltrexone bromide is absorbed rapidly, with peak concentrations $\left(\mathrm{C}_{\max }\right)$ achieved at approximately 0.5 hours following subcutaneous administration. The $\mathrm{C}_{\max }$ and area under the plasma concentration-time curve (AUC) increase with dose increase from $0.15 \mathrm{mg} / \mathrm{kg}$ to $0.5 \mathrm{mg} / \mathrm{kg}$ in a dose-proportional manner. Absolute bioavailability 
of a $0.30 \mathrm{mg} / \mathrm{kg}$ subcutaneous dose versus a $0.30 \mathrm{mg} / \mathrm{kg}$ intravenous dose is $82 \% .^{32,37}$

Methylnaltrexone undergoes moderate tissue distribution. The steady-state volume of distribution is approximately $1.1 \mathrm{~L} / \mathrm{kg}$. Methylnaltrexone is minimally bound to human plasma proteins $(11.0 \%$ to $15.3 \%)$ as determined by equilibrium dialysis. $32,37,48$

Methylnaltrexone is metabolized to a modest extent in humans based on the amount of methylnaltrexone metabolites recovered from excreta. Conversion to methyl-6-naltrexol isomers and methylnaltrexone sulfate appears to be the primary pathway to metabolism. Each of the methyl-6-naltrexol isomers has somewhat less antagonist activity than the parent compound, and low exposure in plasma of approximately $8 \%$ of the drug-related materials. Methylnaltrexone sulfate is an inactive metabolite and present in plasma at a level of approximately $25 \%$ of drug-related materials.

Methylnaltrexone is eliminated primarily as the unchanged active substance. Approximately half of the dose is excreted in the urine and somewhat less in feces. The terminal disposition half-life $\left(\mathrm{t}_{1 / 2}\right)$ is approximately 8 hours. ${ }^{49}$

\section{Adverse effects}

The most common adverse effects are reported to be abdominal cramps and flatulence. ${ }^{32,40,44,45,49}$

In a phase III placebo-controlled trial in 133 patients with opioid-induced bowel dysfunction and advanced illness, abdominal pain was reported in $17 \%$ of patients (vs $13 \%$ placebo group), flatulence in $13 \%$ of patients (vs $7 \%$ of placebo group), and nausea in $11 \%$ (vs $7 \%$ of placebo group). ${ }^{39}$ Other, rare adverse side effects might be seen only with long-term use of methylnaltrexone and in larger populations than those previously studied. Further research is urgently needed to be able to develop guideline-supported therapeutic recommendations for long-term use of methylnaltrexone for treatment of opioid-induced constipation in advanced illness.

\section{Conclusion}

Opioid-induced constipation is a frequent symptom in patients with advanced illness undergoing analgesic treatment with opioids and is mediated predominantly by opioid receptors in the gut. Opioid-induced constipation has to be treated rigorously or, as far possible, avoided altogether by means of prophylactic treatment. Although many treatment strategies are available, opioid-induced constipation still poses therapeutic challenges, particularly in the treatment of patients with poor health status and advanced illness. Thorough knowledge of the pathophysiology of the symptoms of opioid-induced constipation is essential for targeted treatment. An alternative therapeutic strategy to conventional oral laxatives has evolved by selectively blocking peripheral opioid-receptors while maintaining desired action of opioids on central receptors that mediate analgesia. This concept has been validated by the clinical efficacy of methylnaltrexone. Methylnaltrexone may represent an important therapeutic option for patients with advanced illness who are suffering from opioid-induced constipation and resistant to conventional oral laxative therapy.

Methylnaltrexone is better than placebo for reversal of opioid-mediated increase of gastrointestinal transit time and constipation. The advantage of methylnaltrexone over other conventional oral laxatives is that it can be given via different routes, which might be beneficial for terminally ill patients. Methylnaltrexone is an effective and a less invasive measure compared with rectal intervention, the effects of which may reduce patient quality of life. However, despite its high effectiveness, the use of methylnaltrexone may be limited by expense.

\section{Disclosures}

The authors report no conflicts of interest.

\section{References}

1. Mancini I, Bruera E. Constipation in advanced cancer patients. Support Care Cancer. 1998;6:356-364.

2. Vainio A, Auvinen A. Prevalence of symptoms among patients with advanced cancer: an international collaborative study. J Pain Symptom Manage. 1996;12:3-10.

3. Fallon MT. Constipation in cancer patients: prevalence, pathogenesis, and cost-related issues. Eur J Pain. 1999;3(suppl):3-7.

4. Goodman ML, Wilkinson S: Laxatives for the management of constipation in palliative care patients. The Cochrane Library. 2004;1-11.

5. Bruera E, Suarez-Almazor M, Velasco A, et al. The assessment of constipation in terminal cancer patients admitted to a palliative care unit: a retrospective review. J Pain Symptom Manage. 1994;9:515-519.

6. Goodman M, Low J, Wilkinson S. Constipation management in palliative care: a survey of practices in the United Kingdom. J Pain Symptom Manage. 2005;29:238-244.

7. Larkin PJ, Sykes NP, Centeno C, et al; European Consensus Group on Constipation in Palliative Care. The management of constipation in palliative care: clinical practice recommendations. Palliat Med. 2008;22:796-807.

8. Mancini I, Bruera E. Constipation. In: Ripamonti C, Bruera E, eds. Gastrointestinal Symptoms in Advanced Cancer Patients. New York: Oxford University Press; 2002:193-206.

9. Chang L. From Rome to Los Angeles - The Rome III Criteria for the Functional GI Disorders. Gastroenterology. 2006;130:1480-1491.

10. Kurz A, Sessler DI. Opioid-induced bowel dysfunction: pathophysiology and potential new therapies. Drugs. 2003;63:649-671.

11. Mikus G. Combining opioid agonists and antagonists as a solution for opioid-induced constipation. European Gastroenterology and Hepatology Review. 2009:71-74.

12. Ramsin B, Trescot AM, Datta S, et al. Opioid complications and side effects. Pain Physician. 2008;11:S105-S120

13. Thomas J. Opioid-induced bowel dysfunction. J Pain Symptom Manage. 2008;35:103-113. 
14. Fallon MT, Hanks GW. Morphine, constipation and performance status in advanced cancer patients. Palliat Med. 1999;13:159-160.

15. Stewart WF, Libermann JN, Sandler RS, et al. Epidemiology of constipation (EPOC) Study in the United States: relation of clinical subtypes to socioeconomic features. Am J Gastroenterol. 1999;94:3530-3539.

16. Wanitschke R, Goerg KJ, Loew D. Differential therapy of constipationa review. Int J Clin Pharmacol Ther. 2003;41:14-21.

17. Clemens KE, Klaschik E. Management of constipation in palliative care patients. Curr Opin Support Palliat Care. 2008;2:22-27.

18. Clemens KE, Klaschik E. Managing nausea, emesis and constipation in palliative care. Dtsch Arztebl. 2007;104:269-278.

19. Manara L, Bianchi G, Ferretti P, Tavani A. Inhibitation of gastrointestinal transit by morphine in rats results primarily from direct drug action on gut opioid investigational sites. $J$ Pharmacol Exp Ther. 1986;237:945-949.

20. Tavani A, Bianchi G, Ferretti P, Manara L. Morphine most effective on gastrointestinal propulsion in rats by intraperitoneal route: evidence for local action. Life Sci. 1980;27:2211-2217.

21. Kaufman PN, Krevesky B, Malmud LS, et al. Role of opiate receptors in the regulation of colonic transit. Gastroenterology. 1998;94: $1351-1356$

22. Jurna I, Baldauf J. Retardiert freigesetztes Naloxon oral: Aufhebung der Obstipation durch orales Morphin ohne Beseitigung der Analgesie. Der Schmerz. 1993;7:314-21.

23. Meissner W, Schmidt U, Hartmann M, et al. Oral naloxone reverses opioid-associated constipation. Pain. 2000;84:105-109.

24. Shaiova L, Rim F, Friedman D, Jahdi M. A review of methylnaltrexone, a peripheral opioid receptor antagonist, and its role in opioid-induced constipation. Palliate Support Care. 2007;5:161-166.

25. Herndon CM, Jackson KC, Halllin PA. Management of opiodinduced gastrointestinal effects in patients receiving palliative care. Pharmacotherapy. 2002;22:240-250.

26. Becker G, Blum HE. Novel opioid-antagonists for opioid-induced bowel dysfunction and postoperative ileus. Lancet. 2009;373:1198-1206.

27. Brown DR, Goldberg LI. The use of quaternary narcotic antagonist in opiate research. Neuropharmacology. 1985;24:181-192.

28. Yuan CS, Foss JF. Methylnaltrexone: investigation of clinical applications. Drug Dev Res. 2000;50:133-141.

29. DeHaven-Hudkins DL, DeHaven RN, Little PJ, Techner LM. The involvement of the opioid receptor in gastrointestinal pathophysiology: therapeutic opportunities for antagonism at this receptor. Pharmaco Ther. 2008;117:162-187.

30. Yuan CS, Israel RJ. Methylnaltrexone, a novel peripheral opioid receptor antagonist for the treatment of opioid side effects. Expert Opin Investig Drugs. 2006;15:541-552.

31. Reichle FM, Conzen PF. Methylnaltrexone, a new peripheral $\mu$-receptor antagonist for the prevention and treatment of opioid-induced extracerebral side effects. Curr Opin Investig Drugs. 2008;9:90-100.

32. Yuan SC, Doshan H, Charney MR, et al. Tolerability, gut effects, and pharmacokinetics of methylnaltrexone following repeated intravenous administration in humans. J Clin Pharmacol. 2005;45:538-546.
33. Holzer P. New approaches to the treatment of opioid-induced constipation. Eur Rev Medi Pharmacol Sci. 2008;12:119-127.

34. Rosow CE, Gomery P, Chen TY, Stefanovich P, Stambler N, Israel R. Reversal of opioid-induced bladder dysfunction by intravenous naloxone and methylnaltrexone. Clin Pharmacol Ther. 2007;82:48-53.

35. Murphy DB, Sutton JA, Prescott LF, Murphy MB. Opioid-induced delay in gastric emptying: a peripheral mechanism in humans. Anesthesiology. 1997;87:765-770.

36. Yuan CS, Foss JF, O'Connor M, Toledano A, Roizen MF, Moss J. Methylnaltrexone prevents morphine-induced delay in oral-cecal transit time without affecting analgesia: a double-blind randomized placebocontrolled trial. Clin Pharmacol Ther. 1996;59:469-475.

37. Yuan CS, Foss JF, Osinksi J, Toledano A, Roizen MF, Moss J. The safety and efficacy of oral methylnaltrexone in preventing morphineinduced delay in oral-cecal transit-time. Clin Pharmacol Ther. 1997;61: 467-475.

38. Yuan CS, Wei G, Foss JF, O’Connor M, Karrison T, Osinski J. Effects of subcutaneous methylnaltrexone on morphine-induced peripherally mediated side-effects: a double-blind randomized placebo-controlled trial. J Pharmacol Exp Ther. 2002;300:118-123.

39. Thomas J, Karver S, Cooney GA, et al. Methylnaltrexone for opioid-induced constipation in advanced illness. $N$ Engl $J$ Med. 2008;358:2332-2343.

40. Yuan CS, Foss JF, O'Connor M, et al. Methylnaltrexone for reversal of constipation due to chronic methadone use: a randomized controlled trial. JAMA. 2000;283:367-372.

41. Yuan CS, Foss FJ. Oral methylnaltrexone for opioid-induced constipation. JAMA. 2000;11:1383-1384.

42. Berde C, Nurko S. Opioid side effects - mechanism-based therapy. N Engl J Med. 2008;358:2400-2402.

43. Beattie DT, Cheruvu M, Mai N, et al. The in vitro pharmacology of the peripherally restricted opioid receptor antagonists, alvimopan, ADL 08-0011and methylnaltrexone. Naunyn-Schmiedeberg's Arch Pharmacol. 2007;375:205-220.

44. McNicol ED, Boyce D, Schumann R, Carr DB. Mu-opioid antagonists for opioid-induced bowel dysfunction. Cochrane Database Syst Rev. 2008;2:CD006332.

45. Herbert MK, Holzer P. Standardized concept for the treatment of gastrointestinal dysmotility in critically ill patients - current status and future options. Clin Nutr. 2008;27:25-41.

46. Yuan CS, Foss JF, O'Connor M, Osinksi J, Roizen MF, Moss J. Effects of intravenous methylnaltrexone on opioid-induced gut motility and transit time changes in subjects receiving chronic methadone therapy: a pilot study. J Pain. 1999;83:631-635.

47. Neary P, Delaney CP. Alvimopan. Expert Opin Investig Drugs. 2005; 14:479-488

48. Kotake AN, Kuwahara SK, Burton E, McCoy CE, Goldberg LI. Variations in demethylation of N-methylnaterxone in mice, rats, dog, and humans. Xenobiotica 1989;19:1247-1254.

49. European Medicines Agency (EMEA). URL: http://www.emea.europa.eu/, accessed 19 September 2009
Therapeutics and Clinical Risk Management

\section{Publish your work in this journal}

Therapeutics and Clinical Risk Management is an international, peerreviewed journal of clinical therapeutics and risk management, focusing on concise rapid reporting of clinical studies in all therapeutic areas, outcomes, safety, and programs for the effective, safe, and sustained use of medicines. This journal is indexed on PubMed Central, CAS,
Dovepress

EMBase, Scopus and the Elsevier Bibliographic databases. The manuscript management system is completely online and includes a very quick and fair peer-review system, which is all easy to use. Visit http://www.dovepress.com/testimonials.php to read real quotes from published authors. 